\title{
Ngữ âm tiếng Thái Lan trong sự so sánh với Tiếng Việt
}

\author{
Nguyễn Tưong Lai ${ }^{a *}$ \\ ${ }^{a}$ PGS.TS, Trương Đại học Khoa học Xã hội và Nhân văn \\ *Email:nguyentuonglai@yahoo.com
}

\section{Thông tin bài viết}

Ngày nhận bài:

02/12/2017

Ngày duyệt đăng:

12/6/2018

Tù khoá:

Tiếng Thái Lan, tiếng Việt

Nam, ngũ âm.

\section{Tóm tắt}

Mối quan hệ giữa Thái Lan và Việt Nam đến năm 2016 đã vừa tròn 40 năm. Trong 40 năm, qua nhu cầu học tiếng Thái Lan của người Việt Nam ngày càng được gia tăng. Báo cáo khoa học này nhằm góp phần hỗ trợ việc dạy và học tiếng Thái Lan đạt được hiệu quả tốt. Báo cáo mô tả một số đặc điểm cơ bản về mặt ngữ âm của tiếng Thái Lan đồng thời tiến hành so sánh với tiếng Việt để nêu ra những điểm tương đồng và khác biệt về mặt ngữ âm của hai ngôn ngữ. Những vấn đề được quan tâm trong báo cáo đó là: Các hệ thống âm vị phụ âm, nguyên âm và thanh điệu của tiếng Thái Lan. So sánh để phát hiện những nét tương đồng và khác biệt về các hệ thống âm vị phụ âm, nguyên âm và thanh điệu giữ tiếng Thái Lan và tiếng Việt.
Thái Lan và Việt Nam đã có mối quan hệ ngoại giao đến năm 2016 là vừa tròn 40 năm. Mối quan hệ này ngày càng phát triển cả về chiều rộng lẫn chiều sâu. Ngoài mối quan hệ về chính trị và kinh tế thì mối quan hệ về văn hóa và giáo dục ngày càng được đẩy mạnh. Hiện nay ở Việt Nam đã có nhiều trường đại học đưa chương trình dạy và học tiếng Thái Lan vào chương trình đào tạo của mình và hàng năm đã có nhiều sinh viên tốt nghiệp đại học biết sử dụng tốt tiếng Thái Lan làm việc trong các cơ quan ngoại giao và các công ty có vốn đầu tư của Thái Lan ở Việt Nam. Nhu cầu học tiếng Thái Lan ở Việt Nam ngày càng tăng không chỉ ở trong các trường đại học mà còn lan tỏa ra cả ngoài xã hội. Để góp phần nâng cao thêm hiệu quả của việc dạy và học tiếng Thái Lan dành cho người Việt Nam chúng tôi xin giới thiệu hệ thống ngữ âm của tiếng Thái Lan trong thế so sánh với tiếng Việt nhằm rút ra những nét tương đồng và khác biệt, qua đó đề xuất một số cách biên soạn bài giảng và cách học tiếng Thái Lan sao cho có kết quả tốt nhất.

Tiếng Thái Lan cùng có quan hệ nguồn gốc với ngôn ngữ của các dân tộc thuộc nhóm Thái ở Đông Nam Á, Nam Trung Quốc và Đông Bắc Ân Độ. Tuy các dân tộc Thái có địa bàn cư trú rộng lớn như vậy nhưng chỉ có người Thái ở Thái Lan và Lào là xây dựng được quốc gia độc lập tồn tại cho đến ngày nay. Điều kiện lịch sử ấy đã tạo cho tiếng Thái Lan có được một tiến trình phát triển ngày càng hoàn chỉnh để trở thành ngôn ngữ quốc gia với những vai trò to lớn như nhiều ngôn ngữ quốc gia khác trên thế giới.

Tiếng Thái Lan có cùng một loại hình ngôn ngữ với tiếng Việt; đó là loại hình đơn lập. Tiếng Việt từ xa xưa đã có mối quan hệ tiếp xúc với các ngôn ngữ thuộc nhóm Thái cho nên tiếng Việt và tiếng Thái Lan lại càng có nhiều nét tương đồng. Hiện nay đa số các nhà ngôn ngữ học đều coi tiếng Việt có quan hệ nguồn gốc với các ngôn ngữ Môn - Khmer và sau này tiếng Việt đã tiếp xúc với tiếng Thái ở Việt Nam, chịu ảnh hưởng từ tiếng Thái rõ nhất là về các mặt ngữ âm, từ vựng và các cơ chế cấu tạo từ. Do đó, tiếng nói của người Thái Lan và người Việt đương nhiên có nhiều nét tương đồng xuất phát từ nguyên nhân cùng loại hình ngôn ngữ và sự tiếp xúc ngôn ngữ giữa người Việt với các đồng tộc của người Thái Lan ở Việt Nam. Để thấy rõ điều này, chúng ta hãy đặt tiếng Thái Lan trong thế đối chiếu so sánh với tiếng Việt, từ đó sẽ thấy được không chỉ những đặc 
điểm giống nhau mà còn cả những đặc điểm riêng ở từng ngôn ngữ. Kết quả của việc làm này sẽ là cơ sở để chúng ta có được những giải thích xác đáng khi nghiên cứu các vấn đề về ngữ âm và từ vựng tiếng Việt, đồng thời nó sẽ giúp chúng ta có được những phương pháp dạy và học tiếng Thái Lan cho người Việt và tiếng Việt cho người Thái Lan một cách dễ dàng và nhanh nhất.

Trong bài này tôi sẽ cố gắng đưa ra những hiện tượng tiêu biểu nhất để làm dẫn chứng và phân tích nhằm nêu bật lên những đặc điểm giống và khác nhau giữa tiếng Thái Lan và tiếng Việt về mặt ngữ âm học.

1. Tiếng Thái Lan và tiếng Việt cùng thuộc loại hình ngôn ngữ đơn lập nhưng chúng lại gần gũi nhau hơn cả so với các ngôn ngữ đơn lập khác. Trước hết, tiếng Thái Lan và tiếng Việt là các ngôn ngữ đơn âm tiết tính triệt để, và thứ đến là cả hai ngôn ngữ đều thuộc loại ngôn ngữ có thanh điệu. Nhờ có hai đặc trưng ngữ âm này mà tiếng Thái Lan và tiếng Việt được xếp vào cùng một nhóm trong nội bộ các ngôn ngữ đơn lập.

Với đặc trưng là ngôn ngữ đơn âm tiết tính nên âm tiết của tiếng Thái Lan và tiếng Việt có một vai trò rất quan trọng và đặc biệt. Cũng như tiếng Việt, âm tiết tiếng Thái Lan cũng là một đơn vị ngữ âm có tính độc lập rất cao; đó là trong tiếng Thái Lan lời nói được nói ra bằng một loạt các âm tiết tách biệt và rõ ràng. Ta có thể nghe người Thái Lan nói một câu như sau:

ในน้ำมีปลา ในนามีข้าว "dưới nước có cá, trên đồng có lúa"

Cũng giống như tiếng Việt, câu này được tạo thành bằng những âm tiết độc lập như sau:

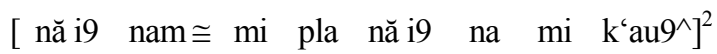

Duới nước có cá trên đồng có lúa

Tuy vậy, do về sau này tiếng Thái Lan chịu ảnh hưởng nhiều tiếng Pali và Sanskrit vốn thuộc loại ngôn ngữ đa tiết nên đã có một số hiện tượng gần với hiện tượng nối âm. Ví dụ các từ sau đây vốn là từ thuần Thái nhưng đã được phát âm theo kiểu nối âm: จักจั่น "con ve sầu”, nếu đọc theo chữ viết thì là [căk $\cup$ căn

\footnotetext{
${ }^{2}$ Chúng tôi dùng các ký hiệu phiên âm quốc tế để phiên âm tiếng Thái Lan. Ngoài ra để ghi các thanh điệu của tiếng Thái Lan, chúng tôi sử dụng các ký hiệu sau: Thanh tương đương với thanh huyền của tiếng Việt có ký hiệu $\exists$; Thanh tương đương với thanh sắc của tiếng Việt có ký hiệu $\cong$; Thanh tương đương với thanh hỏi của tiếng Việt có ký hiệu \& ; Thanh tương đương với thanh nặng của tiếng Việt có ký hiệu $\cup$; Thanh Thô (Xiểng Thô) có ký hiệu ^ Các ký hiệu này được đặt bên trên, ở cuối âm tiết .
}

$\exists$ ] nhưng đọc đúng phải là [căk $\cup$ kacăn $\exists$ ]; Có nghĩa là âm cuối [k] của âm tiết [căk ] được phát âm lặp lại để kết hợp với nguyên âm [a] tạo thành một âm tiết lướt [ka] nối với âm tiết [căn $\exists$ ]. Cũng vậy, từ

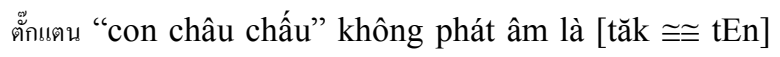
mà phát âm là $[$ tăk $\cong \cong k a t E n]$. Hai trường hợp này giống với trường hợp uุตรี "con gái” có gốc Pali và Sanskrit được phát âm theo kiểu nối âm là [butu tri ]; tức là phụ âm cuối [t] của âm tiết [but ] được nối vào âm tiết sau [ri] thành [tri]. Mặc dù vậy, các hiện tượng này chỉ nhận thấy rõ ở chữ viết còn trong phát âm thì người Thái Lan vẫn có xu hướng phát âm thành các âm tiết tách rời tương đương nhau, ví dụ [căk

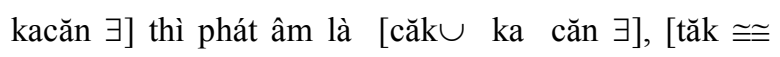

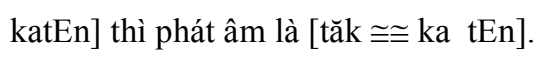

Cũng có thể nói rằng đa số âm tiết tiếng Thái Lan đều có khả năng biểu hiện ý nghĩa. Đặc điểm này giống với tiếng Việt. Nhưng nếu nói rằng tất cả các âm tiết của tiếng Thái Lan đều có nghĩa (như đã nói với tiếng Việt) thì e rằng khó có thể chấp nhận được. Theo tôi, thực ra tiếng Thái Lan cũng như tiếng Việt vốn là hai ngôn ngữ có bước chuyển từ đa tiết sang đơn tiết. Bằng chứng của nó là các âm tiết thuần Thái hoặc thuần Việt không có nghĩa trong các từ đa tiết vẫn đang tồn tại ở hai ngôn ngữ này với tư cách là dấu vết còn lại của một ngôn ngữ đa tiết. Số lượng âm tiết kiểu này ở tiếng Thái Lan còn được giữ lại nhiều hơn tiếng Việt. Sau này tiếng Thái Lan lại tiếp xúc với các ngôn ngữ đa tiết là tiếng Pali, Sanskrit rồi các ngôn ngữ châu Âu khác nữa làm cho tiếng Thái Lan dường như bị đa tiết hoá trở lại. ${ }^{3}$

Âm tiết tiếng Thái Lan cũng có một cấu trúc chặt chẽ như âm tiết tiếng Việt. Cụ thể, cấu trúc âm tiết tiếng Thái Lan bao gồm phần phụ âm đầu và phần vần; trong phần vần có phần âm chính là vị trí của nguyên âm và phần cuối là vị trí của các phụ âm kết thúc âm tiết, hay nói cho đúng hơn là vị trí xuất hiện những cách kết thúc âm tiết khác nhau. Tiếng Thái Lan cũng có thanh điệu, vị trí của nó là bao trùm lên toàn bộ âm tiết như tiếng Việt.

Cấu trúc âm tiết tiếng Thái Lan có điểm khác với cấu trúc âm tiết của tiếng Việt là trong phần vần không có thành phần âm đệm. Tiếng Thái Lan có âm

\footnotetext{
${ }^{3}$ Theo thống kê của chúng tôi thì với số lượng 5.000 từ tiếng Thái Lan những từ kiểu này đã chiếm khoảng $38,7 \%$. Xin xem: Quế Lai. Những vấn đề cấu tạo từ tiếng Thái Lan hiện đại. - Nxb Khoa học Xã hội; Hà Nội; 1994 (Các thống kê 1, 2 và 3 tr. 57)
} 
tiết kiểu như กวาด [k **atบ] "quét", giống như âm tiết [ku99atu] "quạt" của tiếng Việt. Đối với tiếng Việt có thể dễ dàng coi âm [u9] là thành phần âm đệm của âm tiết; nhưng đối với tiếng Thái Lan thì có thể không coi như vậy. Trong tiếng Thái Lan âm [u9] này chỉ đi với hai phụ âm là $[\mathrm{k}]$ và $\left[\mathrm{k}^{\text {‘ }}\right]$ do đó tần số xuất hiện của nó rất thấp so với âm [u9] của tiếng Việt vốn có sự kết hợp với nhiều phụ âm khác nhau. Vậy nên coi [u9] của tiếng Thái Lan là yếu tố môi hóa tạo thành hai âm vị phụ âm môi hóa $[\mathrm{k} *]$ và $\left[\mathrm{k}^{\text {c }}\right.$ **]. Như vậy, tuy số lượng âm vị có tăng lên 2 đơn vị nhưng cấu trúc âm tiết của tiếng Thái Lan đã đơn giản hơn nhờ việc lược bớt đi được một thành phần là thành phần âm đệm. Như vậy cấu trúc âm tiết tiếng Thái Lan sẽ là $\mathrm{CVC}$ trong khi cấu trúc âm tiết tiếng Việt là CWVC. ${ }^{4}$

2. Đi vào cụ thể từng thành phần khác của âm tiết chúng ta sẽ thấy những nét tương đồng và khác biệt được thể hiện như sau:

\subsection{Hệ thống âm vị phụ âm đầu}

Phần đầu của âm tiết tiếng Thái Lan là vị trí xuất hiện của 23 âm vị phụ âm đơn khác nhau về vị trí và phương thức cấu âm. Đó là các âm vị phụ âm như sau:

\begin{tabular}{|c|c|c|c|c|c|c|c|c|c|}
\hline & & inh vi & & & & & Mật & Gốc lưỡi & \\
\hline & & ong thirc & & Môi & Bet & Quăt & Iิน̛̛̛̃ $\mathrm{i}$ & & $\begin{array}{l}\text { Thanh } \\
\text { Lầu }\end{array}$ \\
\hline & & Bât & & & $t^{*}$ & & & & \\
\hline Tác & Òn & $\begin{array}{l}\text { Không } \\
\text { bât hơi }\end{array}$ & $\underset{\text { thanht }}{\text { Vô }}$ & & $t$ & 口 & c & $\mathrm{k}$ & 1 \\
\hline & & & $\begin{array}{l}\text { Hồu } \\
\text { thanth }\end{array}$ & b & d & & & & \\
\hline & & fang (nit & & $\mathrm{m}$ & $\mathrm{n}$ & & ) & $\mathrm{N}$ & \\
\hline & & Vô tl & anh & f & $\mathrm{s}$ & * & & $\Xi$ & h \\
\hline & On & Hồu ! & hanh & $\mathrm{v}$ & z & 1 & & $\otimes$ & \\
\hline dat & & Vang & & & 1 & & & & \\
\hline
\end{tabular}

Còn tiếng Việt thì có 22 âm vị phụ âm đầu như sau: 5

\begin{tabular}{|c|c|c|c|c|c|c|c|c|c|c|}
\hline \multirow{3}{*}{\multicolumn{3}{|c|}{$v_{i}$ tor }} & \multicolumn{2}{|c|}{$\mathrm{Nat}$} & \multicolumn{5}{|c|}{ Lwoni } & \multirow{3}{*}{ Hàu } \\
\hline & & & \multirow[b]{2}{*}{ Mesi } & \multirow[b]{2}{*}{ Rauz } & \multicolumn{2}{|c|}{ B'́lu turởi } & \multirow{2}{*}{$\begin{array}{l}\text { Mlłłt } \\
\text { turói }\end{array}$} & \multicolumn{2}{|c|}{ Góbe lười } & \\
\hline & & & & & Kanz & Lqi & & $\begin{array}{l}\text { Khäos: } \\
\text { mắt bós }\end{array}$ & ب⿱艹 & \\
\hline \multirow[t]{3}{*}{ Tis } & \multirow{2}{*}{ tó } & Khừz bật bớ & $p$ & & 1 & & e & k & x. & 1 \\
\hline & & Bät bố & $D^{\circ}$ & & $t^{2}$ & & $c^{\prime}$ & $\mathrm{k}^{2}$ & k* & \\
\hline & & lờu thanh & b & & d & & & & & \\
\hline \multirow[t]{2}{*}{ Xát } & & Vốthanb & & $\mathrm{f}$ & , & & & & & b \\
\hline & & lơvu thanh & B & & & & i & & & \\
\hline \multicolumn{3}{|c|}{ Mái } & $\mathrm{m}$ & & a & & & $\mathrm{N}$ & & \\
\hline \multicolumn{3}{|c|}{ Dén } & & & & $\mathrm{t}$ & & & & \\
\hline \multicolumn{3}{|c|}{ Ruag } & & & & $x$ & & & & \\
\hline
\end{tabular}

\footnotetext{
${ }^{4}$ Tạm ghi ký hiệu cho thành phần âm đệm là w.

${ }^{5}$ Theo: Đoàn Thiện Thuật. Ngũ âm tiếng Việt. Nxb Đại học Quốc gia Hà Nội, tái bản lần thứ 4, 2007, tr. 153
}

Như vậy về mặt số lượng thì tiếng Thái Lan và tiếng Việt gần như tương đương về số lượng âm vị phụ âm đầu. ${ }^{6}$ Nhưng cụ thể sẽ có những khác biệt sau:

- Những âm vị phụ âm đầu của tiếng Thái Lan không có trong tiếng Việt: Đó là các âm vị /p/,/ p \%/, /

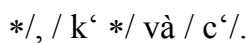

- Có hai âm vị so với hai âm vị tương ứng trong tiếng Việt thì chỉ khác nhau một chút về vị trí cấu âm: đó là âm vị /B/ của Thái Lan là âm xát, hữu thanh, môi môi so với âm vị /v/ của Việt là âm xát, hữu thanh, môi răng; âm vị / $\mathrm{j} /$ của Thái Lan là âm xát, hữu thanh, mặt lưỡi so với âm vị /z/ của Việt là âm xát, hữu thanh, đầu lưỡi.

- Có hai âm vị khác nhau một chút về phương thức cấu âm: đó là âm vị / k của Thái Lan là âm gốc lưỡi, tắc, vô thanh, bật hơi so với âm vị / $\Xi$ / của Việt là âm gốc lưỡi, xát, vô thanh, không bật hơi; âm vị / r / của Thái Lan là âm đầu lưỡi, lợi, rung so với âm vị / / / của Việt là âm đầu lưỡi, quặt, xát.

Như trên đã nói, đứng ở vị trí đầu âm tiết của tiếng Thái Lan còn có hai âm vị phụ âm môi hóa là $/ \mathrm{k}$ */ và $/ \mathrm{k}^{\natural} * /$. Yếu tố tròn môi này trong tiếng Việt được xử lý là âm vị tạo nên một thành phần của âm tiết được gọi là âm đệm. Ngoài ra, tiếng Thái Lan còn có một loạt các phụ âm kép (phụ âm hai tiêu điểm) đứng ở vị trí đầu âm tiết có giá trị âm vị học độc lập. Đó là các phụ âm kép có thành tố thứ hai là $[\mathrm{r}]$ hoặc $[1]$ : $[\mathrm{pl}]$; [pr]; [ p'l]; [ p'r]; [tr]; [kl]; [kr]; [ k'l]; [ $\left.\mathrm{k}^{\prime} \mathrm{r}\right]$. Tiếng Việt hiện đại không còn các phụ âm kép đứng đầu âm tiết nữa.

\subsection{Hệ thống âm vị phu âm và bán nguyên âm cuối}

Là loại hình ngôn ngữ đơn lập đơn âm tiết tính, tiếng Thái Lan và tiếng Việt có phụ âm đầu không hoàn toàn giống với phụ âm cuối. Phụ âm cuối không có giai đoạn hơi bật ra ngoài tạo thành âm thanh như khi phát âm các phụ âm đầu. Nói cách khác, cũng như tiếng Việt, các phụ âm cuối tiếng Thái Lan đều là phụ âm đóng. ${ }^{7}$ Do có đặc

${ }^{6}$ Âm tắc hầu / / / cũng có trong tiếng Thái Lan và nó cũng xuất hiện ở vị trí cuối âm tiết. Còn trong tiếng Việt thì âm này không xuất hiện ở vị trí cuối âm tiết. Cũng vậy, âm vị phụ âm đầu / $\mathrm{p} / \mathrm{chỉ}$ có ở các từ phiên âm trong tiếng Việt và phụ âm [ $\mathrm{p}$ ] chỉ xuất hiện ở vị trí cuối âm tiết vì vậy tiếng Việt không có âm vị phụ âm đầu / p /.

${ }^{7}$ Đặc điểm này cũng đã được nhà ngôn ngữ học người Thái Lan Rương-đệt Păn-khườn-khặt cho là một trong những đặc điểm chung của các ngôn ngữ nhóm Thái. Xin xem: เรืองเดช ปันเขื่อนขัติย์ ภาษาถิ่นตระกูลไทย สถาบันวิจัยภาษาและวัฒนธรรมเพื่อพัฒนาชนบท มหาวิทยาลัยมหิดล กรุงเทพๆ พ. ศ. ๒๕๓๓ 
điểm này mà âm tiết mới được tách ra thành từng khúc đoạn riêng biệt. Vậy có thể coi các phụ âm cuối là những cách khác nhau để kết thúc âm tiết. Nếu các phụ âm đầu có các phương thức cấu âm thì các phụ âm cuối lại có các phương thức ngắt âm.

Trong tiếng Thái Lan có những cách khác nhau để kết thúc âm tiết. Âm tiết có thể được kết thúc bằng cách thuần tuý nghỉ phát âm; tức là khi kết thúc âm tiết, các bộ vị cấu âm không ở vị trí của một phụ âm nào, đó là âm tiết mở kiểu như: ตา [ta] (mắt); โต [to] (to); มี [mi] (có); เท[ t‘e] (đổ đi);... Âm tiết cũng có thể được kết thúc bằng các phương thức ngắt âm như: bộ vị cấu âm dừng lại ở vị trí phát âm các âm tắc mũi $[\mathrm{m}],[\mathrm{n}],[\mathrm{N}]$, ví dụ: ตาม [tam] (theo), นาน [nan] (lâu), ทาง [t‘aN ] (đường, lối); bộ vị cấu âm dừng lại ở vị trí phát âm các âm tắc miệng $[\mathrm{p}],[\mathrm{t}],[\mathrm{k}]$,

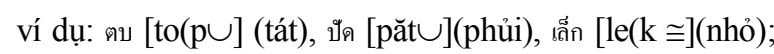
bộ vị cấu âm dừng lại ở vị trí của âm tắc hầu [/], ví dụ: เตะ [te(? $]$ (đá bóng); bộ vị cấu âm dừng lại ở vị trí của các bán nguyên âm [ u9 ] và [ i9 ], ví dụ: ข้าว [k`au9 ^] (lúa); ตาย [ta i9] (chết). Những cách kết thúc âm tiết này được coi là những âm vị đứng ở vị trí cuối âm tiết. Ngoại trừ âm vị / / /, các âm vị trên đây của tiếng Thái Lan đều có trong tiếng Việt.

Âm vị /// xuất hiện rất nhiều trong các âm tiết và các từ của tiếng Thái Lan, tạo nên một đặc trưng ngữ âm riêng biệt cho tiếng Thái Lan. Âm vị /// có mặt trong các từ đơn âm tiết như: แกะ $[\mathrm{kE}(/ \cup](\mathrm{khắc}$, chạm); เกาะ $[\mathrm{k} \square(/]$ (bám, đậu); ... và có mặt rất nhiều

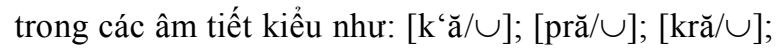
$[\mathrm{mă} / \cong] ;[\mathrm{p}$ 'ră/ $\cup]$; v.v... Những âm tiết kiểu này đứng ở vị trí đầu trong các từ song tiết (mà cả hai âm tiết đều không có nghĩa) như: ประจำ [pră/ $\cup$ căm] (thường, thường xuyên); กระเฉด $[\mathrm{kră} / \cup$ c'et $U$ (rau dút); มะลิ $\left[\mathrm{mă} / \cong 1 \mathrm{i}(/ \cong]\right.$ (hoa nhài); พระเจ้า $\left[\mathrm{p}\right.$ 'ră/ $\cong$ cau9 $\left.{ }^{\wedge}\right]$ (Phật, thần, vua);... Trong những từ thuộc loại này một số lớn các âm tiết đầu có thể phát âm thành âm tiết lướt, ví dụ như: คดี $\left[\mathrm{k}^{‘} \mathrm{a} / \cup \operatorname{di}\right]$ (phương diện); ขณะ $\left[\mathrm{k}^{`} \breve{a} / \cup\right.$

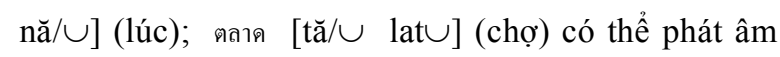
thành $\left[\mathrm{k}^{\prime}\right.$ adi], $\left[\mathrm{k}^{\prime}\right.$ ană/ $\left.\cup\right]$ và $[$ talat $\cup]$. Những từ nói trên đây có rất nhiều trong tiếng Thái Lan, trong khi đó không hề thấy có trong tiếng Việt; nhưng cũng có thể cho là cùng một dạng với các từ có một số lượng rất ít trong tiếng Việt như: bù nhìn, bồ hóng, bồ hòn, mà cả, cà cuống...

\subsection{Hệ thống âm vị nguyên âm}

Phần âm chính của âm tiết tiếng Thái Lan về mặt ngữ âm có 9 cặp nguyên âm đơn ngắn dài như sau:

\begin{tabular}{|c|c|c|c|c|c|c|}
\hline \multirow{2}{*}{ 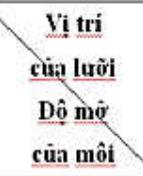 } & \multicolumn{2}{|c|}{ Dòng truớc } & \multicolumn{2}{|c|}{ Dòng giưa } & \multicolumn{2}{|c|}{ Dòng sau } \\
\hline & Dìi & Noğ́n & Dài & Ngẩn & Dài & Noân \\
\hline Khép & i & i< & $\propto$ & $\propto($ & $\mathrm{u}$ & $\mathrm{u}($ \\
\hline Trung binh & e & ef & $\Phi$ & $\Phi($ & 0 & of \\
\hline $\mathbf{M} \tilde{\alpha}$ & E & $E($ & a & ă & [ & $\square($ \\
\hline
\end{tabular}

Nguyên âm đôi: Gồm có 3 âm vị nguyên âm đôi dài là / $\underline{\text { ie }} /, /$ $/ \underline{\Phi} /, /$ uo $/ .^{8}$

Như vậy, phần âm chính của tiếng Thái Lan và tiếng Việt đều có số lượng các nguyên âm đơn dài, ngắn và nguyên âm đôi dài như nhau. Nhưng điểm khác là ở chỗ số lượng các âm vị nguyên âm ngắn. Tiếng Việt chỉ có 2 âm vị nguyên âm ngắn / $\Phi($ /; / ă / cộng với 9 âm vị nguyên âm dài trên đây tạo thành 11 âm vị nguyên âm đơn. ${ }^{9}$ Trong khi đó tiếng Thái Lan có 6 âm vị nguyên âm ngắn:/ i( /; / e( /; / œ( /; / ă /; / u( /; / o( / cộng với 9 âm vị nguyên âm dài trên đây tạo thành 15 âm vị nguyên âm đơn. 3 nguyên âm đôi ngắn là những nguyên âm chỉ xuất hiện trong các âm tiết có phần cuối là âm tắc hầu ///, ví dụ: เดี๊ยะ $[\mathrm{die} / \cong](\mathrm{mau}, \mathrm{nhanh}) ;$ เปือะ $[\mathrm{p} \propto \underline{\Phi} / \cup] ;$ จั๊ว $[\underline{\mathrm{cuO} /} \cong]$. Trong tiếng Thái Lan những nguyên âm đôi ngắn không phải là những âm vị.

\subsection{Hệ thống thanh điệu}

Tiếng Thái Lan có tất cả 5 thanh, đó là:

1- Xiểng Xả-măn, tương đương với thanh bằng của tiếng Việt. Ví dụ: มา [ma] (đến); นา [na] (ruộng); ตา [ta] (mắt).

2- Xiểng Êệk, tương đương với thanh huyền của tiếng Việt. Ví dụ: ด่า [da $\exists$ ]

(chửi); ข่า [ $\left.\mathrm{k}^{`} \mathrm{a} \exists\right]$ (riềng); ผ่า [ $\left.\mathrm{p}^{`} \mathrm{a} \exists\right]($ chẻ, xẻ).

\footnotetext{
8 Chúng tôi tạm dùng dấu gạch ngang đặt dưới các ký hiệu ghi nguyên âm đôi.

${ }^{9}$ Theo Đoàn Thiện Thuật tiếng Việt còn có 2 âm vị nguyên âm ngắn nữa là / $\mathrm{E}$ / / và / $\square$ / / Xem: Đoàn Thiện Thuật, sách đã dẫn.
} 
3- Xiểng Thô. Ví dụ: หน้า $\left[\mathrm{na}^{\wedge}\right]$ (mặt); บ้า $\left[\mathrm{ba}^{\wedge}\right]$ (điên); ห้า [ha^] (số 5). Thanh này không có trong tiếng Việt nhưng rất hay gặp trong tiếng Thái Lan và tạo thành một đặc trưng riêng của thanh điệu Thái Lan.

4- Xiểng Tri, tương đương với thanh sắc của tiếng Việt. Ví dụ: กุ๊e [ku(i9 @]

(ma, quỷ); จ๊วก [cuok $\cong]$ (trắng nõn); โต๊ะ [to(/ $\cong]($ cái bàn).

5- Xiểng Chặt-ta-va, tương đương với thanh hỏi của tiếng Việt. Ví dụ: จ๋า $\quad\left[\begin{array}{ll}\text { ca } & \&\end{array}\right]($ ơi,dạ); เดี๋ย [dieu9 \&] (một lát, một lúc); ตั๋ว [tuo \&](vé).

Tiếng Thái Lan có 5 thanh trong khi tiếng Việt có 6 thanh. Trong khi tiếng Việt không có thanh Thô như của tiếng Thái Lan thì tiếng Thái Lan lại không có thanh ngã và thanh nặng của tiếng Việt. Thực ra tiếng Thái Lan cũng có thanh tương đương với thanh nặng của tiếng Việt nhưng nó không có giá trị âm vị học độc lập như thanh nặng của tiếng Việt; Nó là một trong hai biến thể của thanh Êệk, đó là:

- Thanh Êệk tương đương với thanh nặng của Việt có điểm kết thúc thấp hơn hẳn so với thanh Ệ̣̂k tương đương với thanh huyền. Thanh này chỉ xuất hiện trong các âm tiết mà phần cuối có các âm vị tắc miệng /p/, $/ \mathrm{t} /, / \mathrm{k} /$ và tắc hầu ///. Ví dụ: หาบ [hap $\cup$ (Gánh); จับ $[$ căp $\cup](b a ̆ ́ t) ;$ ขาด $\left[k^{\prime} a t \cup\right]($ rách $) ;$ ตัด $[t a ̆ t \cup](c a ̆ ́ t) ;$ ตาก $[\operatorname{tak} \cup]($ phơi); ตัก [tăk $\cup](m u ́ c) ;$ จะ [că/ $\cup]$ (sẽ). Riêng âm vị /// có độ tắc họng mạnh hơn nên làm cho các nguyên âm đi cùng luôn là nguyên âm ngắn và thanh điệu kết thúc nhanh và thấp hơn các trường hợp có các âm vị $/ \mathrm{p} /, / \mathrm{t} /, / \mathrm{k} /$. Trường hợp này gần giống với các trường hợp gọi là âm tiết mở có thanh nặng trong tiếng Việt.

- Thanh Êệk tương đương với thanh huyền như đã mô tả trên đây xuất hiện trong các âm tiết mà phần cuối có các âm vị tắc mũi /m/, /n/, / N / và các âm vị bán nguyên âm / u9 /, / i 9 /.

Ngoài ra trong tiếng Thái Lan còn có một biến thể của thanh Tri; đó là thanh Tri xuất hiện trong âm tiết có phần cuối là âm vị ///. Âm vị /// đã làm cho thanh Tri trong trường hợp này có độ tắc họng khá mạnh, nguyên âm đi cùng luôn là nguyên âm ngắn. Ví dụ: มะ [mă/ @] (quả); ละ

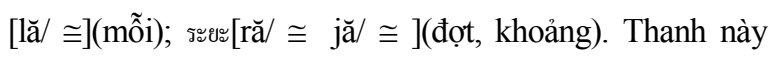

giống như thanh sắc của tiếng Việt nhưng có độ tắc họng mạnh. Tiếng Việt hoàn toàn không có loại âm tiết và thanh điệu kiểu này.

Những đặc điểm ngữ âm khác nhau giữa tiếng Thái Lan và tiếng Việt như đã nêu trên đây là nguyên nhân chính làm cho người Thái Lan và Việt Nam gặp khó khăn khi học tiếng nói của nhau. Người học sẽ phát âm khó khăn những âm không có âm tương ứng trong tiếng mẹ đẻ. Vì vậy các sách học tiếng cần biên soạn chú trọng vào những nét khác biệt này để người học được tập trung luyện tập và làm quen nhanh với các cách phát âm mới lạ. Bài viết này chỉ mới đưa ra những âm vị có trong tiếng Thái Lan mà không có trong tiếng Việt nhằm giúp người Việt Nam lưu ý khi học tiếng Thái Lan và biên soạn các sách học tiếng Thái Lan. Những đề xuất cụ thể về phương pháp biên soạn và hướng dẫn luyện tập phát âm tiếng Thái Lan sẽ được chúng tôi trình bày trong một dịp khác.

\section{TÀI LIỆU THAM KHẢO}

1. Nguyễn Tương Lai (2014), Sách học tiếng Thái Lan tập 1, Nxb Đại học Quốc gia Hà Nội;

2. Đoàn Thiện Thuật (2007), Ngr̃ âm tiếng Việt, Nxb Đại học Quốc gia Hà Nội;

3.กาญจนา นาคสกุล ระบบเสียงภาษาไทย โครงการตำราคณะอักษรศาสตร์ ลำดับ ที่ ๓๘ จุฬาลงกรณ์มหาวิทยาลัย กรุงเทพฯ พ. ศ. ๒๕๕๕の;

4. กำชัย ทองหล่อ หลักภายาไทย ฉบับพิมพ์ครั้งที่ 10 บริษัท รวมสาส์น กรุงเทพฯ พ.ศ. 2540 ;

5.เรืองเดช ปันเขื่อนขัติย์ ภาษาศาสตร์ภาษาไทย สถาบันวิจัยภาษาและวัฒนธรรมเพื่อพัฒนา ชนบท มหาวิทยาลัยมหิดล กรุงเทพฯ พ.ศ. ๒๕๕๕ด;

6.รืองเดช ปันเขื่อนขัติย์ ภาษาถิ่นตระกูลไทย
สถาบันวิจัยภาษาและวัฒนธรรมเพื่อพัฒนา ชนบท มหาวิทยาลัยมหิดล กรุงเทพฯ พ. ศ. ๒๕ัต๑. 


\section{Thai phonetics in comparison with Vietnamese}

Nguyen Tuong Lai

\section{Article info}

Recieved:

02/12/2017

Accepted:

$12 / 6 / 2018$

Keywords:

Thai language,

Vietnamese, phonetics.

\begin{abstract}
The relationship between Vietnam and Thailand has reached 40 years by 2016 . During the last 40 years, Vietnamese demand for learning Thai language has increased more and more. This report aimed to support the teaching and learning of Thai language more effectively. The report mentioned basic characteristics of Thai phonetics and at the same time compared the similarities as well as differences between the language and Vietnamese. Focused areas of the report covered: Thai phonemes including consonants, vowels and tones; Comparing and highlighting the similarities and differences between Thai and Vietnamese consonants, vowels and tones.
\end{abstract}

